\title{
Superação da resistência qualitativa da cultivar de trigo 'BRS 194' por uma nova raça de Puccinia triticina
}

\author{
Breakdown of qualitative leaf rust resistance in the wheat cultivar 'BRS 194' by a new race \\ of Puccinia triticina
}

\author{
Márcia Soares Chaves ${ }^{{ }^{*}}$ Caroline de Lima Wesp $^{\text {I }}$ Amarilis Labes Barcellos ${ }^{I I}$ \\ Pedro Luiz Scheeren ${ }^{\mathrm{I}}$ Márcio Só e Silva ${ }^{\mathrm{I}}$ Eduardo Caierão ${ }^{\mathrm{I}}$
}

\section{- NOTA -}

\section{RESUMO}

A população de Puccinia triticina, agente causal da ferrugem da folha do trigo, é extremamente dinâmica na região do Cone Sul da América do Sul, onde o surgimento de novas raças é freqüente. A cultivar de trigo "BRS 194" foi a segunda variedade com maior disponibilidade de sementes para plantio no Rio Grande do Sul e em Santa Catarina em 2005, por apresentar características como rusticidade, elevado rendimento de grãos e resistência qualitativa a todas as raças de P. triticina ocorrentes no Brasil e em outros países da América do Sul. Em 2005, pústulas de ferrugem da folha foram observadas sobre plantas desta cultivar, tanto em lavouras quanto em campos experimentais, indicando a possível superação de sua resistência. O objetivo deste trabalho foi identificar a raça de $\boldsymbol{P}$. triticina presente em amostras oriundas de "BRS 194" e verificar se esta se tratava de uma nova virulência do patógeno, a qual teria superado sua resistência. Oito amostras de ferrugem provenientes da cultivar "BRS 194" foram enviadas em 2005 à Embrapa Trigo, Passo Fundo, Rio Grande do Sul, para isolamento e identificação por meio da Série Internacional de Hospedeiros Diferenciais específica para este patógeno. Todas as amostras apresentaram a mesma combinação de virulência, a qual correspondeu ao código MFP-CT, conforme o Sistema Norte-Americano de nomenclatura do patógeno. Esta foi a primeira vez que este código foi detectado no Brasil, caracterizando o surgimento de uma nova raça de P. triticina virulenta à "BRS 194". Outras cultivares de trigo, também amplamente semeadas, foram inoculadas com a nova raça, sendo que algumas foram suscetíveis e outras resistentes. Entre as cultivares resistentes estão "Fundacep 30" e "IPR 84", as quais permanecem também resistentes a todas as raças do patógeno ocorrentes no Brasil.

Palavras-chave: ferrugem da folha, Triticum aestivum, virulência, resistência raça-específica.

\section{ABSTRACT}

The population of Puccinia triticina, the causal agent of wheat leaf rust, is extremely dynamic in the South Cone region of South America, where the appearance of new races is frequent. The wheat cultivar 'BRS 194' was the second variety in availability of seeds for planting in Rio Grande do Sul and Santa Catarina States in 2005, because it has good agronomic characteristics as rusticity, high yield and resistance to all races of $\boldsymbol{P}$. triticina occurring in Brazil and other countries in South America. In 2005, pustules of leaf rust were observed in this cultivar on farms and in experimental fields, indicating the probable breakdown of its resistance. The objective of this research was to identify the race of $\boldsymbol{P}$. triticina present in samples from 'BRS 194' and verify if it was a new virulence of the pathogen able to overcome its resistance. Eight samples of leaf rust from 'BRS 194' were sent to Embrapa - National Wheat Research Center, Passo Fundo, Brazil for isolation and identification in International Sets of Differential Hosts specific for this pathogen. All samples showed the same virulence combination, which corresponded to MFP-CT according to the North-American System of nomenclature for the pathogen's races. That was the first time that this letter code was detected in Brazil, characterizing the emergence of a new race of $\boldsymbol{P}$. triticina virulent to 'BRS 194'. Other popular varieties were inoculated with the new race, some were susceptible and others were resistant. Among the resistant cultivars were 'Fundacep 30' and 'IPR 84', which also remain resistant to all races of the pathogen occurring in Brazil.

Key words: Triticum aestivum, virulence, race-specific resistance.

Na região do Cone Sul da América do Sul, as condições de ambiente são extremamente favoráveis

'Embrapa Trigo, CP 451, 99001-970, Passo Fundo, RS, Brasil. E-mail: mchaves@cnpt.embrapa.br. *Autor para correspondência.

IIOR Melhoramento de Sementes Ltda., Passo Fundo, RS, Brasil. 
à ocorrência de epidemias de ferrugem da folha do trigo, causadas por Puccinia triticina Erikss. (=Puccinia recondita Rob. ex Desm. f. sp. tritici). A ocorrência de epidemias também é favorecida porque nessa região áreas extensas são cultivadas com os mesmos genótipos de trigo, sendo que muitos são suscetíveis; ocorrem plantas de trigo voluntárias nas entressafras e as épocas de cultivo são subseqüentes, formando uma "ponte verde" para patógenos biotróficos como $\boldsymbol{P}$. triticina. Além disso, este patógeno tem grande habilidade em superar genes de resistência específicos (SINGH et al., 2002), sendo que o conjunto desses fatores contribui para que haja grande quantidade de inóculo disponível ao longo de todo o ano, o que facilita a seleção e a fixação de isolados com novas combinações de virulência (CHAVES \& BARCELLOS, 2006). A população de $\boldsymbol{P}$. triticina neste ambiente é extremamente dinâmica, sendo freqüente o surgimento de novas raças, as quais podem se tornar importantes devido à sua ampla disseminação e/ou pela superação da resistência de uma cultivar amplamente cultivada. (CHAVES et al., 2005).

O método mais eficiente e econômico para a redução das perdas provocadas pela ferrugem da folha nas lavouras é a utilização de cultivares resistentes (NELSON, 1973b). Esta prática, além de evitar as perdas causadas pela doença, não aumenta os custos de produção, garantindo maior retorno aos produtores (NELSON, 1973a; PRIESTLEY \& BAYLES, 1988). Na interação Puccinia triticina x trigo, a caracterização da reação de genótipos quanto à resistência ou suscetibilidade é baseada em diferentes tipos de pústulas, os quais foram descritos por ROELFS et al. (1992) como "tipos de infecção" (do inglês infection type). Segundo o autor, a reação de resistência é caracterizada por pústulas correspondentes aos tipos de infecção (0), (;), (1) e (2) e suas variações em intensidade para (+) ou para (-) e a reação de suscetibilidade é caracterizada por pústulas correspondentes aos tipo de infecção (3) e (4) e suas variações em intensidade para (+) ou para (-). Mais de um tipo de infecção pode ocorrer em um mesmo genótipo e até em uma mesma folha, caracterizando reações de resistência ou suscetibilidade moderadas, reações intermediárias entre resistência e suscetibilidade ou reação heterogênea, em que não existe uma definição entre uma ou outra reação, pois todos os tipos de infecção estão presentes.

A cultivar de trigo “BRS 194”, lançada pela Embrapa Trigo em 2000, foi recomendada para cultivo em todas as regiões tritícolas dos Estados do Rio Grande do Sul e de Santa Catarina. O cruzamento para sua obtenção (CEP14/BR 23//CEP 17), teve por objetivo reunir as características favoráveis de três cultivares de boa adaptação ao cultivo do trigo no Sul do Brasil, sendo que as duas últimas foram as cultivares mais semeadas no Rio Grande do Sul no período de 1988 a 1994 (REUNIÃO, 2000). A cultivar “BRS 194” apresenta rusticidade, elevado rendimento de grãos e, por sua crescente aceitação na lavoura, foi a segunda cultivar com maior disponibilidade de sementes para plantio no Rio Grande do Sul e em Santa Catarina em 2005. Devido à sua ampla adaptação às regiões produtoras de trigo, em 2005 foi indicada para cultivo nas regiões 9 e 10 do Mato Grosso do Sul e nas regiões 7 e 8 do Paraná (DEL DUCA et al., 2005).

Até o ano de 2004, a cultivar "BRS 194" apresentava resistência qualitativa a todas as raças de $\boldsymbol{P}$. triticina ocorrentes no Brasil e em outros países da América do Sul, sendo observados pústulas com tipos de infecção correspondentes à reação de resistência e moderada resistência (R-MR) em condições de campo. Entretanto, em 2005, pústulas de ferrugem da folha com tipos de infecção de suscetibilidade foram observadas em plantas desta cultivar, tanto em lavouras quanto em campos experimentais, indicando a possível superação de sua resistência. O objetivo deste trabalho foi identificar a raça $\boldsymbol{P}$. triticina presente nas amostras oriundas da cultivar "BRS 194" e verificar se esta se tratava de uma nova virulência do patógeno, a qual teria superado sua resistência.

Em 2005, foram recebidas na Embrapa Trigo, Passo Fundo, Rio Grande Sul, oito amostras de folhas da cultivar "BRS 194" com sinais de ferrugem da folha, provenientes de experimentos nos municípios de Passo Fundo e São Borja, no Rio Grande do Sul; Chapecó, em Santa Catarina; Campo Mourão, no Paraná; e da cidade argentina de Paraná, em Entre Rios. Também foram recebidas três amostras de lavouras no município de Espumoso, no Rio Grande do Sul.

Para a identificação da raça presente nas amostras, foram realizados isolamentos monopustulares de cada amostra e incremento do inóculo na cultivar suscetível "Coxilha”. Cada isolado foi inoculado individualmente na primeira folha de plântulas de linhas isogênicas que compõem a Série Internacional de Hospedeiros Diferenciais para identificação de raças de $\boldsymbol{P}$. triticina (LONG \& KOLMER, 1989) mais dois grupos suplementares de genes de resistência $\operatorname{Lr}(\operatorname{Lr} 10, \operatorname{Lr} 18, L r 21, \operatorname{Lr} 23$; e Lr14a, Lr14b, Lr26 na cultivar “Alondra”, Lr20). Após a inoculação, as plântulas ficaram em câmara úmida e escura por $18 \mathrm{~h}$ e em seguida foram transferidas para casa-de-vegetação com condições semicontroladas de temperatura $\left(18-25^{\circ} \mathrm{C}\right)$ e luminosidade. Decorridos 15 dias após a inoculação, foi realizada a leitura da reação 
nas séries diferenciais inoculadas com cada amostra, conforme a metodologia descrita por ROELFS et al., 1992.

Os isolados foram identificados por um código de cinco letras, chamado de código Prt, descrito no Sistema Norte-Americano de Nomenclatura para $\boldsymbol{P}$. recondita f. sp. tritici, proposto por LONG \& KOLMER (1989). Foi também atribuída a nomenclatura usada no Brasil, na qual a raça é nomeada pela letra “B” (de Brasil), seguida por um número que representa a ordem de seu surgimento e identificação no Brasil pelo sistema NorteAmericano. Esta nomenclatura informal é útil para posicionar ao longo do tempo o surgimento de uma raça em relação às demais.

Após o isolamento e a caracterização da raça de $\boldsymbol{P}$. triticina presente nas amostras, foi realizada a reinoculação na primeira folha de plântulas da cultivar “BRS 194” para confirmar se este isolado era de fato o responsável por causar o tipo de pústulas de suscetibilidade, excluindo a possibilidade de as amostras terem sido originadas de plantas de outras variedades que, eventualmente, poderiam estar misturadas às de "BRS 194". As demais cultivares de trigo indicadas para cultivo nas regiões Sul e CentroSul do Brasil também for inoculadas com a raça presente nas amostras com o objetivo de caracterizar sua reação.

A reação nas séries diferenciais revelou que todas as amostras tratavam-se da mesma combinação de virulência, a qual correspondeu ao código MFP-CT, conforme o Sistema Norte-Americano de nomenclatura. Este código não havia sido observado anteriormente no Brasil, portanto, os isolados foram considerados uma nova raça de $\boldsymbol{P}$. triticina. A raça MFP-CT é avirulenta aos genes $L r 2 a, L r 2 c, L r 9, \operatorname{Lr} 10, \operatorname{Lr} 11, \operatorname{Lr} 16$, $L r 18$ e $L r 21$, e virulenta a $L r 1, L r 3, L r 3 k a, L r 14 a$, Lr14b, Lr17, Lr20, Lr23, Lr24, Lr26, Lr30 e Alondra e, de acordo com a nomenclatura atribuída no Brasil, foi também chamada de B56. A inoculação da raça MFPCT de $\boldsymbol{P}$. triticina em plântulas de "BRS 194” resultou em pústulas com tipo infecção suscetível, confirmando a superação da sua resistência por esta nova raça do patógeno.

O surgimento de novas raças de $\boldsymbol{P}$. triticina tem ocorrido no Brasil com uma freqüência de zero a duas novas raças/ano (CHAVES \& BARCELLOS, 2006), as quais, eventualmente, apresentam combinações de virulência capazes de superar a resistência de variedades comerciais. As cultivares "Tifton" e "CEP 14” tornaram suscetíveis um ano após o seu lançamento e a cultivar "Alondra”, portadora do gene $L r 26$, teve sua resistência superada mesmo antes de seu cultivo em escala comercial (BARCELLOS et al., 1997). As cultivares “Embrapa 16”, “BRS 49” e “OR” foram amplamente semeadas no Brasil e tornaram-se suscetíveis, respectivamente, após um, dois e três anos de seu lançamento. Situações semelhantes ocorreram no Uruguai, com as cultivares “Estanzuela Pelón 90” e "INIA Mirlo”, em 1999; e na Argentina, com cultivares “Klein Pegaso", "ProINTA Puntal” e "Klein Don Enrique”, em 1999, 2001 e 2002, respectivamente (GERMAN et al., 2004). Mais recentemente no Brasil, em 2003, foi relatada a superação da resistência em fase de plântula da cultivar "Rubi”, cinco anos após seu lançamento, por uma raça de $\boldsymbol{P}$. triticina capaz de vencer a resistência conferida pela combinação dos genes de resistência $L r 3, L r 10, L r 24$ e $L r 26$ (BARCELLOS \& TURRA, 2004).

Novas combinações de virulência de $\boldsymbol{P}$. triticina podem se tornar importantes devido à sua ampla disseminação e/ou pela superação da resistência de uma cultivar semeada em grandes áreas (CHAVES et al., 2005). O impacto do surgimento de MFP-CT parece se enquadrar no segundo caso, pois estima-se que "BRS 194” atingiu em 2005 uma área cultivada de cerca de 100.000ha, sendo a segunda cultivar de trigo mais semeada neste ano no Rio Grande do Sul e em Santa Catarina.

Além de “BRS 194”, outras cultivares amplamente semeadas na região Sul e Centro-Sul do Brasil são suscetíveis a MFP-CT: "BRS 179”, "BRS Louro”, “CD 105”, “Alcover”, “Jaspe”, “Pampeano”, "Fundacep Nova Era”, "Fundacep 51” e "Fundacep 52”. Embora nenhuma delas apresentasse resistência a todas as raças de $\boldsymbol{P}$. triticina como a "BRS 194", a suscetibilidade à MFP-CT contribui para aumentar 0 potencial de inóculo desta nova raça e o risco de epidemias severas. De fato, dados dos levantamentos de raças do patógeno, realizados anualmente pela Embrapa Trigo, revelam que MFP-CT ocorreu em 2005 com freqüência de $0,67 \%$ e no ano seguinte, 2006, a freqüência desta mesma raça elevou-se para 5,31\%.

A cultivar "CD 104”, muito popular e amplamente cultivada na região Centro-Sul do Brasil, apresenta reação intermediária, entre moderada resistência e moderada suscetibilidade à nova raça. As cultivares “BRS 208”, “IPR 85” e “Ônix”, também amplamente semeadas, apresentaram resistência à nova raça do patógeno nos testes em condições controladas. Além destas, também são resistentes em fase de plântula as cultivares “BRS 119”, "BRS 220”, "BRS 248”, "BRS Figueira”, “BRS Guamirim”, “CD 114”, “CEP 24Industrial”, “Fundacep 31”, “Fundacep 32”, “Granito”, “IPR 109”, “IPR 110”, “IPR 118”, “Avante”, “Rubi”, “Safira”, “Fundacep 30” e "IPR 84”, sendo que apenas as duas últimas cultivares continuam resistentes a todas as raças de $\boldsymbol{P}$. triticina que ocorrem no Brasil.

Ciência Rural, v.39, n.1, jan-fev, 2009. 
Do presente trabalho pode-se concluir que: i) a raça de Puccinia triticina presente nas amostras de ferrugem da folha oriundas da cultivar "BRS 194" se tratava de uma nova virulência, correspondente ao código MFP-CT; ii) a raça MFP-CT superou a resistência qualitativa presente na cultivar "BRS 194”.

\section{AGRADECIMENTOS}

Ao Conselho Nacional de Desenvolvimento Científico e Tecnológico (CNPq), pela concessão de bolsa de Desenvolvimento Tecnológico Industrial à segunda autora.

\section{REFERÊNCIAS}

BARCELLOS, A.L. et al. Ferrugem da folha do trigo (Puccinia recondita): durabilidade da resistência. Summa Phytopathologica, Botucatu, v.23, p.101-111, 1997.

BARCELLOS, A.L.; TURRA, C. Ferrugem da folha do trigo Nova raça (nota técnica). In: REUNIÃO DA COMISSÃO SULBRASILEIRA DE PESQUISA DE TRIGO, 36., 2004, Passo Fundo, RS. Ata e resumos... Passo Fundo: Comissão SulBrasileira de Pesquisa de Trigo, 2004. p.86.

CHAVES, M. S. et al. Population dynamics of Puccinia triticina in the South Cone region of South America from 1997 to 2004. In: INTERNATIONAL WHEAT CONFERENCE, 7., 2005, Mar del Plata, AR. Abstracts... Mar del Plata: SAGPyA/ INTA, 2005. p.130.

CHAVES, M.S.; BARCELLOS, A.L. Especialização fisiológica de Puccinia triticina no Brasil em 2002. Fitopatologia Brasileira, Lavras, v.31, n.1, p.57-62. 2006.

DEL DUCA, L. DE J.A. et al. Cultivar de trigo “BRS 194” para as regiões de adaptação 7 e 8 do Paraná e 9 e 10 do Mato Grosso do Sul. In: REUNIÃO DA COMISSÃO CENTRO-SULBRASILEIRA DE PESQUISA DE TRIGO, 20., 2005, Londrina,
PR. Ata e Resumos... Londrina: Embrapa Soja, 2005. V.1. p.295-296.

GERMAN, S. et al. Breakdown of resistance of wheat cultivars and estimated losses caused by recent changes in the leaf rust population in South America. In: INTERNATIONAL CEREAL RUSTS \& POWDERY MILDEWS CONFERENCE, 11., 2004, Norwich, UK. Abstracts... part 2. Norwich: John Innes Centre, 2004. s.A2, p.21.

LONG, D.L.; KOLMER, J.A. A North American system of nomenclature for Puccinia recondita f. sp. tritici. Phythopathology, v.79, p.525-529, 1989.

NELSON, R.R. Introduction. In: NELSON, R.R. (Ed.) Breeding plants for disease resistance. Pennsylvania: The Pennsylvania State University, 1973a. p.3-12.

NELSON, R.R. The meaning of disease resistance in plants. In: NELSON, R.R. (Ed.). Breeding plants for disease resistance. Pennsylvania: The Pennsylvania State University, 1973b. p.13-25.

PRIESTLEY, R.H.; BAYLES, R.A. The contribution and value of resistant cultivars to disease control in cereals. In: CLIFFORD, B.C.; LESTER, E. (Eds.). Control of plant diseases: costs and benefits. Oxford: Blackwell Scientific, 1988. p.53-65.

REUNIÃO DA COMISSÃO SUL-BRASILEIRA DE PESQUISA DE TRIGO, 32., 2000, Cruz Alta, RS. Indicações técnicas... Cruz Alta: Comissão Sul Brasileira de Pesquisa de Trigo, 2000. p.113-120.

ROELFS. A.P. et al. Rust diseases of wheat: concepts and methods of disease management. Mexico, DF: CIMMYT, 1992. 81p.

SINGH, R.P. et al. The wheat rusts. In: CURTIS, B.C.et al. (Eds.). FAO plant production and protection. Roma: FAO, 2002. p. 1-25 (Series, n.30). 